\title{
PERANCANGAN SISTEM INFORMASI STOK ATK DI GUDANG KANTOR BPJS KESEHATAN CABANG DEPOK
}

\author{
Riki Aditiantoro', Syatantra Rahutama ${ }^{2}$, Ahmad Husain ${ }^{3}$ \\ Program Studi Teknik Informatika, Fakultas Teknik dan Ilmu Komputer, \\ Universitas Indraprasta PGRI \\ Jalan Raya Tengah No 80, Kelurahan Gedong, Pasar Rebo, Jakarta Timur \\ rikiaditiantoro@gmail.com ${ }^{1}$, syatantra@yahoo.com ${ }^{2}$, hnr.husen@gmail.com ${ }^{3}$
}

\begin{abstract}
Abstrak
Pada era globalisasi sekarang ini sistem informasi stok Atk sangat dibutuhkan pada jam operasional Kantor untuk pelayanan umum. Masalah yang muncul adalah bagaimana cara merancang sistem informasi stok ATK agar tercatat secara detail dan rapi pada laporan. Dengan merancang sistem ini bertujuan agar stok ATK ini tercatat secara detail dan rapi apabila diperlukan pada jam operasional. Metode yang digunkan adalah Research and Development yaitu suatu metode yang digunakan untuk menghasilkan produk tertentu atau sesuatu sistem yang baru. Hasil penelitian diatas adalah bagaimana untuk merancang dan mengimplementasikan Perancangan Sistem Informasi Stok ATK di Gudang Kantor BPJS Kesehataan Cabang Depok dengan catatan untuk memudahkan pencatatan dan pendataan Stok ATK yang ada, dan sistem laporan yang tersusun sceara detail.
\end{abstract}

Kata Kunci: Perancangan, Sistem Informasi, ATK, Research and Development

\begin{abstract}
In the current era of globalization, the ATK stock information system is very much needed during office operating hours for public services. The problem that arises is how to design a stationery stock information system so that it is recorded in detail and neatly on the report. By designing this system, it is intended that this ATK stock is recorded in detail and neatly when needed during operational hours. The method used is Research and Development, which is a method used to produce a certain product or a new system. The results of the research above are how to design and implement the Design of Information System for ATK Stock in the Depok Branch Office of BPJS Health with notes to facilitate recording and data collection of existing stationery supplies, and a detailed structured reporting system.
\end{abstract}

Keywords: Design, Information System, ATK, Research and Development.

\section{PENDAHULUAN}

Pada era globalisai sekarang ini, kemajuan teknologi dan informasi semakin berkembang. Hal ini sangat memudahkan masyarakat dalam mencari dan mendapatkan informasi tanpa menghabiskan banyak waktu, tenaga, dan uang. Teknologi informasi dan komunikasi bermanfaat dalam berbagai bidang, salah satunya dalam informasi persediaan atau stok ATK di gudang. Sistem informasi persediaan atau stok ATK sangat dibutuhkan dalam operasional kantor setiap harinya. Masalah yang biasanya ada di kantor itu adalah tidak adanya ketersediaan stok ATK yang akan digunakan pada jam operasional. Pencatatan Stok ATK masih konvensional dan yang mengetahui data Stok ATK hanya bagian umum. Sistem ini dibutuhkan untuk mengetahui apakah barang yang akan dipakai dalam operasional pada jam kerja ada atau tidak. Jika informasi Stok ATK ini masih 
konvensional atau belum tersistematis akan mengganggu pelayanan pada jam operasional. Selain itu, akan butuh waktu untuk mengecek di buku stok. Hal ini tentu juga bisa menghambat pelayanan umum terhadap masyarakat. Agar efektif, maka perlu diterapkan sistem informasi stok atau persediaan ATK secara komputerisasi untuk mengatasi hal tersebut. Informasi yang dihasilkan akan membantu bagian umum maupun pegawai yang akan menggunakan ATK yang ada mengontrol dan mengawasi jumlah ATK yang keluar masuk, serta untuk mempermudah bagian umum untuk mengajukan uang belanja ke bagian keuangan apabila stok tinggal sedikit tanpa harus menunggu stok kosong. Menurut (Kriatianto, 2013)," Untuk perancangan suatu sistem adalah suatu proses / fase dimana diperlukan suatu keahlian untuk menciptakan suatu sistem yang baru untuk memilih elemen-elemen, peralatan dan program komputer untuk menciptakan suatu sistem yang baru".

\section{PENELITIAN RELEVAN}

Untuk itu penulis berinisiatif untuk membuat sistem informasi tentang data stok ATK. Untuk mendapatkan referensi penelitian dari jurnal yang berjudul "Perancangan Sistem Invertori Sparepart Elektronik", disusun oleh (Setyadi, 2014) yang berisi tentang bagaimana merancang sistem informasi inventori apakah sesuai dengan kegiatan yang berlangsung atau tidak. Dan jurnal yang berjudul "Analisis Pengendalian Sistem Interen Persediaan Barang Dagangan dan Penerapan Akuntansi Pada PT Cahaya Mitra Alkes", disusun oleh (Manengkey, 2014), yang berisi tentang pengendalian penerapan akuntansi. Dari jurnal tersebut terdapat kesamaan yaitu tentang bagaimana merancang suatu sistem informasi inventori dan penerapan akuntansi untuk sebuah laporan yang detail. Dengan perbedaan obyek yang akan dibuat sistem yaitu ATK.

\section{METODE PENELITIAN}

Metode penelitian yang digunakan penulis dalam penelitian ini adalah Metode Research And Development (R\&D). Metode Research And Development merupakan metode yang digunakan untuk menghasilkan produk tertentu dan menguji keefektifan produk tersebut. Produk tersebuttidak selalu berbentuk benda atau perangkat keras (Hardware), seperti buku, alat tulis, dan alat pembelajaran lainnya. Akan tetapi, dapat pula dalam bentuk perangkat lunak (Software). Menurut (Emzir, 2012), menjelaskan metode R \& D itu sebuah studi sistematis proses desain pengembangan dan evaluasi dengan tujuan untuk membangun basis empiris untuk penciptaan produk dan alat instruksional model baru yang disempurbakan yang mengatur perkembangan mereka.Berbeda dengan penelitian lainnya, $R \& D$ bertujuan untuk mengembangkan dan memvalidasi produk-produk Pendidikan dengan menggunakan langkahlangkah yang disebut siklus R\&D. Siklus ini secara umum terdiri dari kajian terhadap temuan peelitian yang terkait dengan produk yang akan dikembangkan, uji lapangan dalam setting sebenarnya (dimana produktersebut akan digunakan), dan merevisinya untuk memperbaiki kekurangan- kekurangan yang ditemukan dalam tahap uji lapangan. Agar hasilnya lebih teliti dan tepat, siklus tersebut diulang hingga data lapangan menunjukkan bahwa produk tersebut telah mencapai tujuannya.

Metode R\&D ini mempunyai kelebihan sebagai berikut:

1. Mampu mengatasi kebutuhan nyata dan mendesak (relas needs in the here-and-now) melalui pengembangan solusi atas suatu masalah sembari menghasilkan pengetahuan uang bias digunakan di masa mendatang.

2. Mampu menghasilkan suatu produk atau model yang memiliki nilai validasi tinggi, karena melalui serangkain uji coba di lapangan dan divalidasi ahli.

3. Mendorong proses inovasi produk atau model yang tiada henti sehingga diharapkan akan selalu ditemukan model atau produk yang selalu actual dengan tuntutan kekinian.

4. Merupakan penghubung antara penelitian yang bersifat teorotis dan lapangan. 
Untuk metode pengembangan sistem menggunakan SDLC yaitu metodologi pengembangan sistem untuk menyusun sitem yang baru menggantikan yang lama. Dengan tahapan sebagai berikut:

a. Pengumpulan Data

Dalam pengumpulan data ini setiap hari melakukan pengamatan secara langsung ke Gudang ATK dengan tujuan untuk mendapatkan data yang nyata.

b. Analisa Sistem

Untuk Analisa sistem yang akan dibutuhkan banyak melibatkan pihak terkait yang membutukan sistem ini dan berkonsultasi dengan IT untuk sistem yang sedang berlangsung.

c. Merancang Sistem

Dalam perancangan ini berkerjasama dengan IT untuk bagaimana sistem ini bisa digunakan sesuai dengan kebutuhan yang dibutuhkan dengan cara berdiskusi untuk merancang database, merancang antarmuka tentang sistem yang akan dirancang.

d. Menguji dan Mengimplementasikan Sistem

Setelah sistem selesai dilakukan pengujian dan pengimplementasian sistem yang dirancang sudah sesuai dengan yang dibutuhkan atau belum dengan melibatkan pihak-pihak yang membutuhkan.

e. Evaluasi

Dengan tujuan untuk memeriksa apakah masih ada terjadi eror atau tidak terhadap sistem yang dirancang.

f. Pengambilan Keputusan

Dari semua Langkah diatas dapat diambil keputusan bersama apakah sistem yang dirancang sudah sesuai kebutuhan atau belum dengan melibatkan pihak yang bersangkutan.

\section{HASIL DAN PEMBAHASAN}

Proses Bisnis Sistem Berjalan

Dalam proses bisnis menceritakan bagaimana sistem bekerja atau di proses dari sistem yang dibahas. Proses dari sistem informasi stok ATK di BPJS Kesehatan Kantor Cabang Depok, yaitu:

1. Proses Pengecekan Stok ATK

Untuk proses pendataan stok ATK di kantor BPJS ini dilakukan dengan cara:

a. Mendata barang yang datang dari vendor yang sudah bekerja sama apakah barang yang datang sesuai atau tidak dengan yang kita pesan. Proses ini dilakukan dengan mengecek konvensional satu per satu barang dengan tujuan data yang dipesan dan yang datang valid.

b. Memisahkan data barang antara jenis yang satu dengan yang lain.

2. Proses Pendataan Stok

Setelah proses pengecekan dan hasilnya valid langkah selanjutnya pendataan stok ATK untuk update informasi stok ATK yang ada di gudang. Prosesnya sebagai berikut:

a. Data barang yang baru dipesan dan datang dipisahkan antara satu jenis dengan yang lain dengan tujuan agar proses edit maupun input datanya tidak memakan waktu yang lama.

b. Pendataan barang yang sudah di input ke rak yang berisi jenis ATK yang sama.

3. Proses Pemesanan Pengambilan Stok ATK

Pada proses ini pegawai yang akan mengambil ATK harus memesannya terlebih dahulu untuk nantinya diketahui bidang umum apa yang dibutuhkan pegawai pada jam operasional tersebut. Langkahnya sebagai berikut pegawai membuat nota dinas ke bagian umum yang berisi pesanan ATK yang nantinya sebagai pedoman proses pengambilan stok ATK.

4. Proses Laporan

Untuk laporan data stok ATK biasanya dilakukan diakhir bulan dengan tujuan bidang umum mengetahui sisa barang yang ada di gudang stok ATK. Setelah ada datanya itu sebagai data untuk pengajuan uang muka pembelian stok ATK kepada bidang keuangan untuk pemesan ATK kembali ke vendor. 


\section{Entity Relationship Diagram (ERD)}

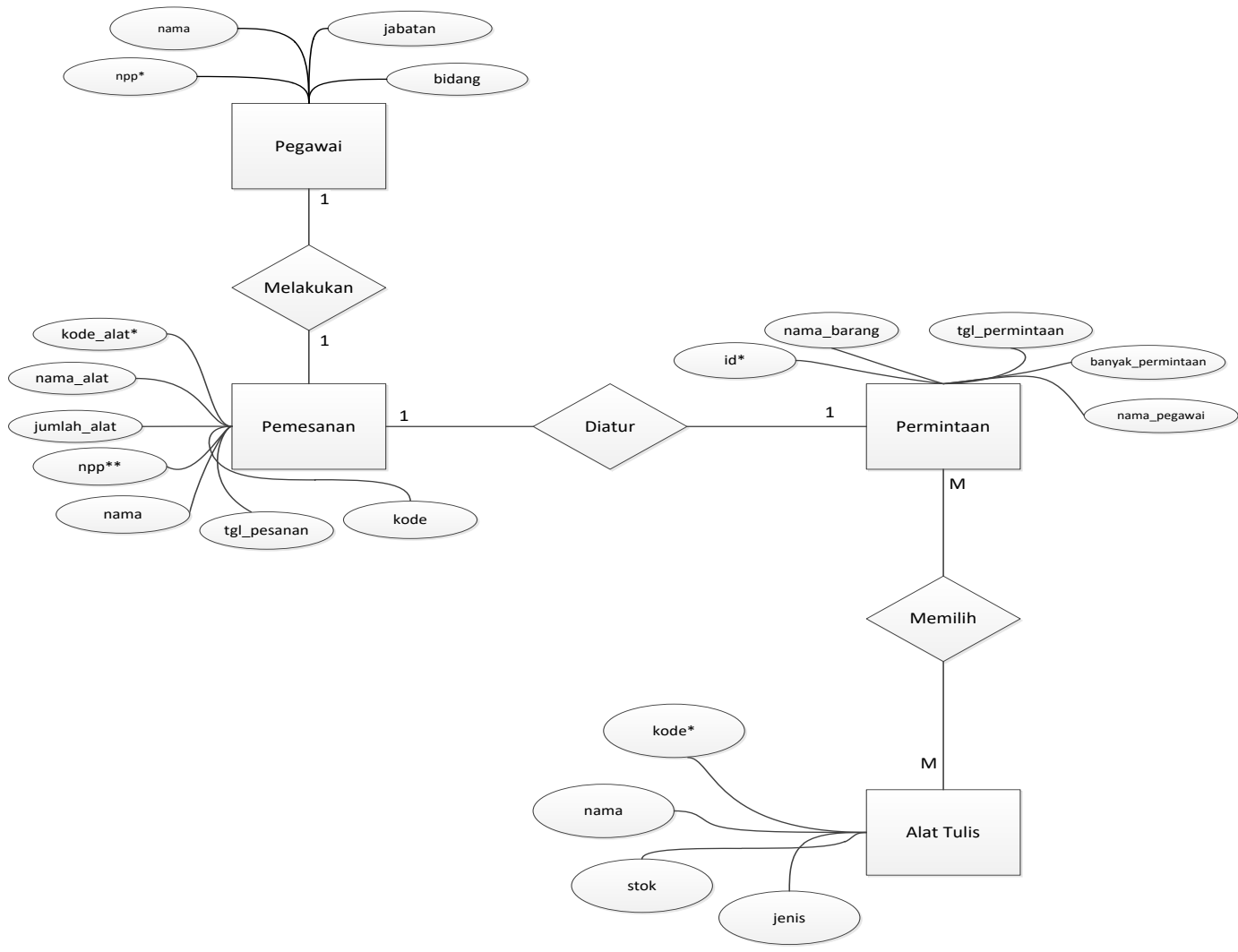

Gambar 1. Entity Relationship Diagram

Dari diagram diatas dapat dijelaskan bahwa pegawai dengan nama, npp, jabatan, bidang dapat memesan suatu atk yg berisi dengan kode alat, nama alat, jumlah alat, dan tanggal memesan untuk dilakukan permintaan barang digudang dan dapat diketahui berapa banyak barang yang digudang setelah itu untuk memilih altak tulis yang dibutuhkan.

\section{Tampilan Layar}

Berikut tahap implementasi dan pengujian pada software program yang telah di buat dengan Bahasa pemograman java.

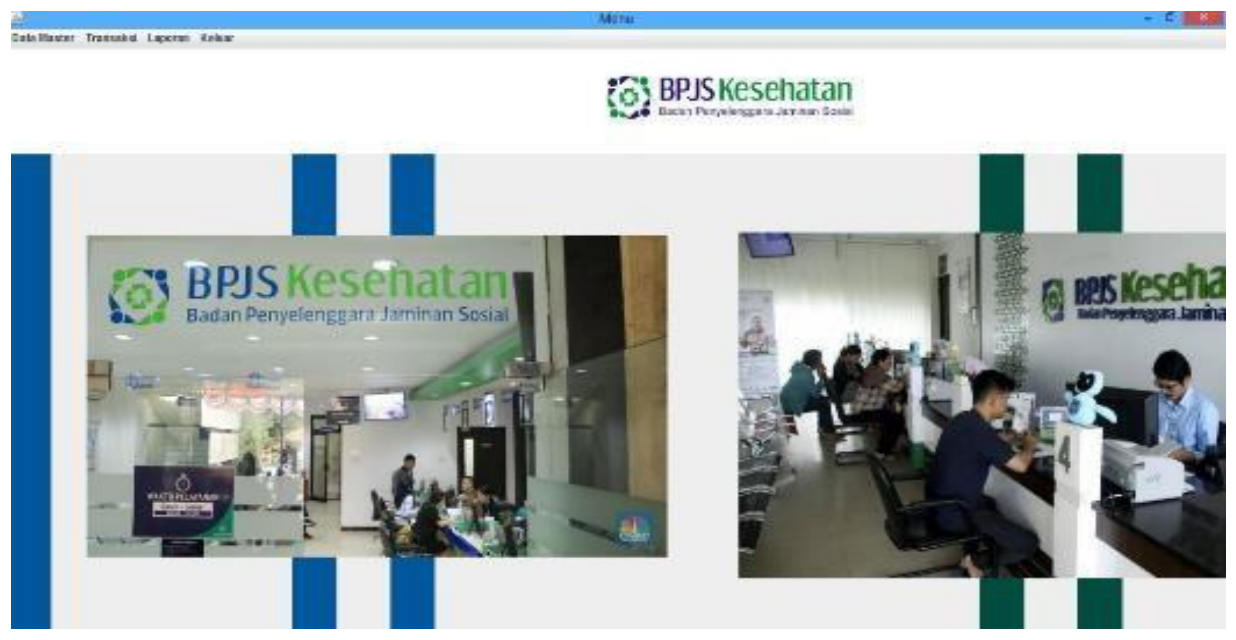

Gambar 2. Tampilan Menu Utama 
Pada menu utama ini terdapat 4 sub menu yaitu Data Master yang berisi data inputan tentang pegawai, data alat tulis, dll, Transaksi berisi tentang inputan transaksi yang dibutuhkan, Laporan berisi tentang laporan data transaksi, Keluar untuk keluar dari aplikasi ini.

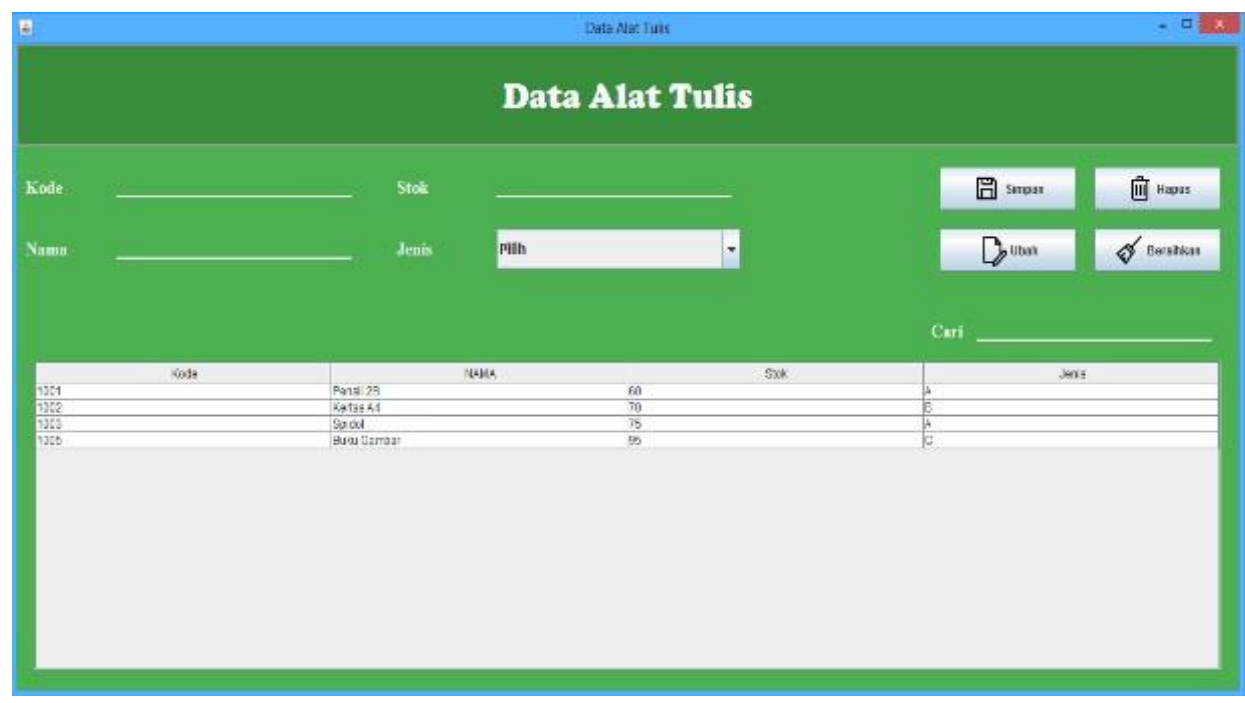

Gambar 3. Form Data Alat Tulis

Dari gambar diatas pada form data alat tulis ini terdapat inputan yang berisi tentang kode, nama, stok, jenis alat tulis, dan menu pencarian untuk melihat data alat tulis.

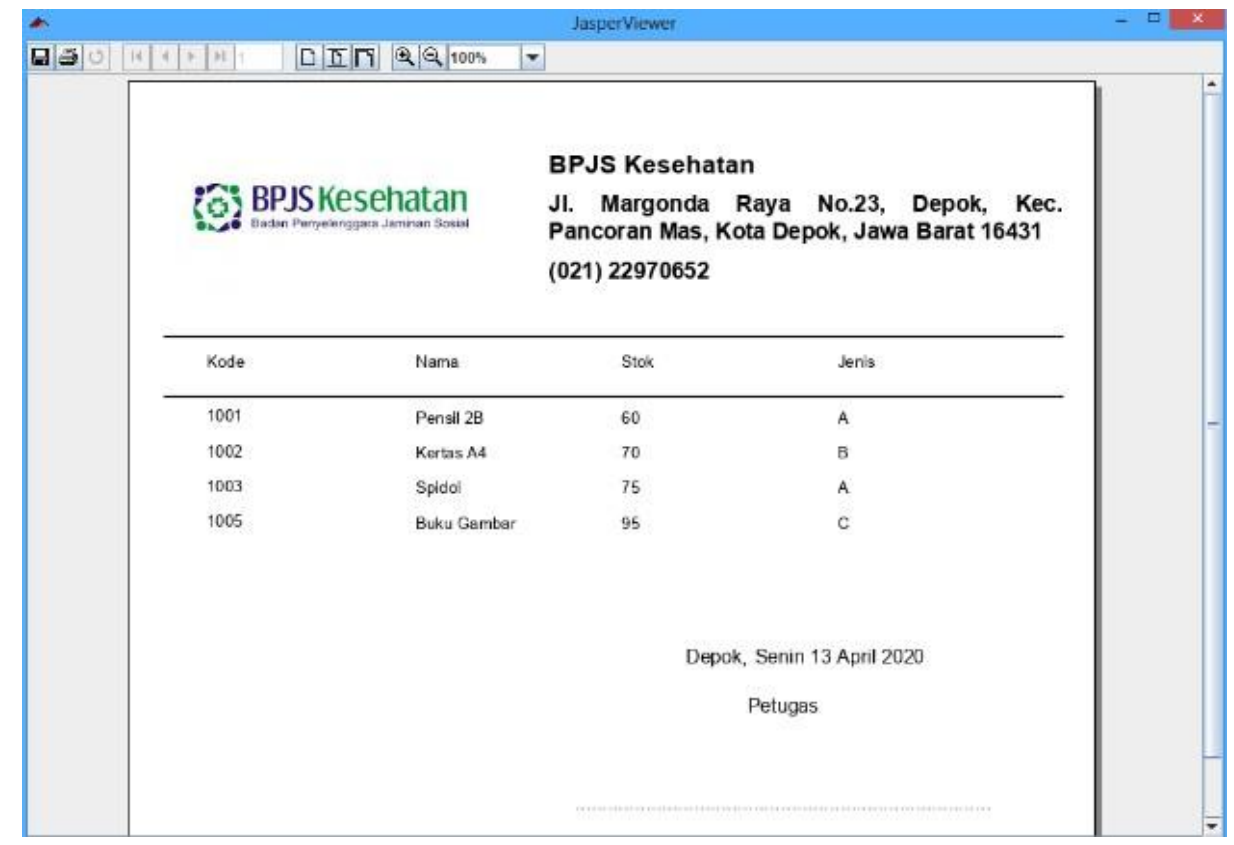

Gambar 4. Laporan Data Alat Tulis

Pada laporan ini terdapat informasi laporan tentang data alat tulis pertanggal yang dipilih dengan keterangan kode, nama, stok, dan jenis alat tulis.

\section{SIMPULAN}

Berdasarkan uraian dan Analisa diatas, maka pada laporan ini yang berjudul "Perancangan Sistem Informasi Stok ATK di Gudang Kantor BPJS Kesehatan Cabang Depok" dapat diambil kesimpulan bahwa dengan adanya sistem informasi in dapat memberikan informasi tentang data 
Stok ATK yang terdata dan tersusun rapi dan dapat memberikan laporan tentang berapa detail Stok ATK yang berada di Gudang untuk menunjang pelayanan publik pada saat jam operasional yang sebelumnya masih manual dan menimbulkan masalah internal.

\section{DAFTAR PUSTAKA}

A. S., Rosa dan Shalahuddin, M. 2013. Rekayasa Perangkat Lunak Terstruktur Dan Berorientasi Objek. Informatika: Bandung.

Abdullah, Thamrin dan Francis Tantri. 2012. Manajemen Pemasaran. Depok : PT Raja Grafindo Persada.

Adrianof, Harkamsyah. 2018. Rancang Bangun Sistem Informasi Promosi dan Penjualan Pada Toko Ruminansia Berbasis Web. Jurnal Pendidikan dan Teknologi Informasi Vol. 5 No. 1.

Andri, Kristanto, 2010. Perancangan Sistem Infromasi. Yogyakarta: Gava Media.

Anhar. 2010. Panduan Menguasai PHP dan MySQL Secara Otodidak. Media Kita : Jakarta Selatan.

Garside, A. K., \&amp; Rahmasari, D. (2017). Manajemen Logistik. Malang : Universitas Muhammadiyah Malang (UMM Press).

Haryanto, Bambang. 2011. Esensi-esensi Bahasa Pemrograman Java. Yogyakarta: Andi.

Hutahean, Jeperson. 2014. Konsep Sistem Informasi. Yogyakarta: Deepublish.

Kristanto. 2013.Perancangan Sistem Informasi dan Aplikasinya. Yogyakarta: Gava Media.

Marbun, S.H, M.H, R. (2010). Tanya Jawab Seputar Tata Cara Pengadaan Barang atau Jasa. Jakarta: Transmedia Pustaka.

Purnomo, H. (2010). Perencanaan dan Perancangan Fasilitas. Yogyakarta: Graha Ilmu.

Raharjo, Budi. 2011.Belajar Otodidak Membuat Database Menggunakan MySQL. Bandung : Informatika.

Sutanto, Azhar. 2013. Sistem Infromasi Akuntansi. Bandung: Lingga Jaya.

Sutabri, Tata. (2012). Konsep Sistem Infromasi. Yogyakarta: CV. Andi Offset 